\title{
Enteral Nutrition in Term Infants with Congenital Heart Disease: Knowledge Gaps and Future Directions to Improve Clinical Practice
}

\author{
Silvia Martini ${ }^{1,+}$, Isadora Beghetti ${ }^{1,+}$, Mariarosaria Annunziata ${ }^{1}$, Arianna Aceti ${ }^{1,2, *(D), ~ S i l v i a ~ G a l l e t t i ~}{ }^{1,2}$, \\ Luca Ragni ${ }^{3}$, Andrea Donti ${ }^{3}$ (D) and Luigi Corvaglia ${ }^{1,2}$
}

1 Department of Medical and Surgical Sciences, University of Bologna, 40138 Bologna, Italy; silvia.martini9@unibo.it (S.M.); isadora.beghetti@studio.unibo.it (I.B.);

mariarosa.annunziata@studio.unibo.it (M.A.); silvia.galletti4@unibo.it (S.G.); luigi.corvaglia@unibo.it (L.C.)

2 Neonatal Intensive Care Unit, IRCCS Azienda Ospedaliero-Universitaria di Bologna, 40138 Bologna, Italy

3 Pediatric Cardiology Unit, IRCCS Azienda Ospedaliero-Universitaria di Bologna, 40138 Bologna, Italy;

luca.ragni@aosp.bo.it (L.R.); andrea.donti@aosp.bo.it (A.D.)

* Correspondence: arianna.aceti2@unibo.it; Tel./Fax: +39-051-342754

+ These authors contributed equally to this work.

Citation: Martini, S.; Beghetti, I.; Annunziata, M.; Aceti, A.; Galletti, S.; Ragni, L.; Donti, A.; Corvaglia, L. Enteral Nutrition in Term Infants with Congenital Heart Disease: Knowledge Gaps and Future Directions to Improve Clinical Practice. Nutrients 2021, 13, 932. https://doi.org/10.3390/nu13030932

Academic Editor: Claudio Romano

Received: 14 February 2021

Accepted: 9 March 2021

Published: 13 March 2021

Publisher's Note: MDPI stays neutral with regard to jurisdictional claims in published maps and institutional affiliations.

Copyright: (C) 2021 by the authors. Licensee MDPI, Basel, Switzerland. This article is an open access article distributed under the terms and conditions of the Creative Commons Attribution (CC BY) license (https:/ / creativecommons.org/licenses/by/ $4.0 /)$.

\begin{abstract}
Optimal nutrition is essential to improve short- and long-term outcomes in newborns with congenital heart disease (CHD). Nevertheless, several issues on nutritional management and concerns about the potential risk of complications related to enteral feeding exist. This narrative review aims to summarize and discuss the available literature on enteral feeding in term infants with CHD. A wide variability in feeding management exists worldwide. Emerging approaches to improve nutritional status and outcomes in infants with CHD include: implementation of a standardized enteral feeding protocol, both preoperative and postoperative, clearly defining time of initiation and advancement of enteral feeds, reasons to withhold, and definitions of feeding intolerance; early minimal enteral feeding; enteral feeding in stable term infants on hemodynamic support; evaluation of enteral feeding in term infants with umbilical arterial catheters and during prostaglandin infusion; assessment and support of oro-motor skills; and promotion and support of breastfeeding and provision of mother's own milk or donor milk when mother's own milk is not available. As evidence from term infants is scarce, available observations and recommendations partially rely on studies in preterm infants. Thus, well-designed studies assessing standardized clinically relevant outcomes are needed to provide robust evidence and shared recommendations and practices.
\end{abstract}

Keywords: congenital heart disease; enteral nutrition; term infants; perioperative feeding management; human milk; necrotizing enterocolitis; prostaglandin; patent ductus arteriosus

\section{Introduction}

Congenital heart disease (CHD) is one of the most common anomalies of human development, with an estimated incidence of 4 to 10 cases per 1000 live births and of about 6 per 1000 live births for moderate and severe forms [1-3]. Most infants born with CHD have a normal weight for gestational age at birth [4], but a relevant proportion of them (between 15\% and 41\%) [5,6] develop malnutrition and growth deficiencies during the first months of life, this leading to delayed or complicated cardiac surgery [5,7]. Several factors are known to contribute to the development of malnutrition in infants with CHD. The increase in sympathetic activity, work of breathing, and the presence of congestive cardiac failure overall contribute to increase the metabolic demand [7]. Failure to thrive is more frequent and severe in neonates with cyanotic CHD compared with non-cyanotic CHD, and it is further worsened by pulmonary hypertension [5]. Structural abnormalities of the gastrointestinal (GI) tract, which occur in $4.2 \%$ of children with CHD, gastroesophageal reflux, and food intolerance can also contribute to inadequate nutrient intake and consequent 
poor growth [8,9]. Moreover, associated genetic syndromes such as Down syndrome, Di George syndrome, Turner syndrome, and trisomy 13 and 18 are independently associated with abnormal growth [10]. A high risk of growth failure persists in the postoperative period [11]; while successful surgical treatment of CHD improves neonates' long-term survival, catch-up growth is impaired in a relevant proportion of these infants [12].

The consequences of malnutrition during critical illness and perioperatively can be more severe in young children and neonates, since in this population greater caloric and nutrients intakes are required to promote an adequate growth and psychomotor development [13]. Hence, suboptimal nutrition in CHD infants has been associated with poorer clinical outcomes: energy and protein deficiency worsens stress-induced catabolic response, impairs wound healing, affects myocardial and muscle function, and may increase the rate of postoperative complications [10]. Moreover, growth failure in infants with CHD has been specifically associated with long-term cognitive impairment [14,15].

Although optimal nutrition is considered essential to improve short- and long-term outcomes in newborns with CHD, large well-designed randomized controlled trials assessing clinically relevant outcomes and interventions are scarce. Position statements and clinical recommendations summarizing the existing evidence have recently become available; nevertheless, several relevant questions on the optimal nutrition in infants with CHD remain unanswered. The aim of this narrative review is to summarize currently available literature on enteral feeding in term infants with CHD, to highlight open issues, and to identify future directions for the improvement of clinical practice.

\section{Literature Review}

Medline, via PubMed, (http: / / www.ncbi.nlm.nih.gov/pubmed/, accessed on 8 March 2021), the Cochrane Library (http:/ / www.cochranelibrary.com/, accessed on 8 March 2021), and Embase (http:/ / www.embase.com/, accessed on 8 March 2021) were interrogated for studies published before 30 November 2020. Search strings were built up by combining all the terms related to enteral feeding and congenital heart disease, using PubMed MeSH terms, free-text words, and their combinations to be as comprehensive as possible. Similar criteria were used for searching the Cochrane Library and Embase. The review was restricted to English-written studies. The reference lists of retrieved studies were searched for further relevant papers. Retrieved papers were categorized according to the following topics, relevant to enteral feeding management in term infants with CHD: preoperative feeding management; postoperative feeding management; impact of breastfeeding and type of milk; and feeding issues.

\section{Preoperative Feeding Management}

Preoperative feeding practices in infants with CHD are very heterogeneous across Intensive Care Units (ICUs) worldwide, and a shared feeding strategy defining the timing for feeding introduction, feeding modality, or optimal intakes is lacking [16,17]. In almost half of European Centers, enteral feeding in infants with CHD is avoided before surgery due to concerns about GI complications and splanchnic ischemia [18,19].

The variation in feeding practices and the lack of a consensus regarding the optimal nutritional support among ICUs caring for CHD infants may contribute to poor growth in the period pending surgery [20]. This is of concern, as a poor nutritional status and a low weight at the time of surgery may lead to increased mortality rates [21,22].

Growing literature supports a beneficial role of preoperative feeding [23-26], which appears to improve postoperative outcomes: CHD infants who were fed before surgery showed more stable postoperative hemodynamics, a better feeding tolerance and wound healing, a decreased duration of mechanical ventilation, a shorter time to reach full calories to wean off parental nutrition, and a shorter hospital stay $[19,23,27,28]$.

Specific feeding protocols have been developed by several institutions caring for CHD patients $[10,19,23,27,29,30]$. 
In hemodynamically stable term neonates with or without pharmacological cardiovascular support, the European Society of Paediatric and Neonatal Intensive Care (ESPNIC) recommends to start enteral nutrition within $24 \mathrm{~h}$ from admission [31]. Potential contraindications to early enteral feeding are GI anatomic abnormalities, maxillofacial abnormalities, increasing abdominal girth, excessive vomiting and/or diarrhea, positive fecal occult blood test, signs and symptoms of necrotizing enterocolitis (NEC), and lactic acidosis [4,26,32-34].

Preoperative enteral feeding should be provided as minimal enteral feeding, with a $10-20 \mathrm{~mL} / \mathrm{kg} /$ day milk intake for few days [35], aiming to increase enteral intakes by 20 to $30 \mathrm{~mL} / \mathrm{kg}$ daily until reaching the volume goal [10]. Trophic feeding has been associated with a faster achievement of full enteral and oral feed, more stable hemodynamics, and a shorter need for respiratory support [23]. Although specific data on the benefits of a human milk (HM) diet in infants with CHD are scarce, HM appears to be the preferred option for the initiation of enteral feeds. Given the vulnerability of the GI tract in infants with $\mathrm{CHD}$, it is reasonable that HM could improve GI function and immune maturation, feeding tolerance, and microbiota composition-similar to preterm infants. The optimal caloric intake needed to avoid growth retardation, however, has not been well established [36]. Swartze et al. reported that infants with CHD need about $150 \mathrm{Kcal} / \mathrm{kg} /$ day in order to achieve a significant gain of weight, length, and subcutaneous tissue mass [37]. Instead, recent recommendations for moderately malnourished children suggest a caloric intake of $90-110 \mathrm{kcal} / \mathrm{kg} /$ day [38], ensuring an enteral protein intake of at least $1.5 \mathrm{~g} / \mathrm{kg} / \mathrm{d}$ to prevent negative protein balance [31].

Marino et al. developed a consensus-based preoperative nutritional strategy for infants with CHD, offering different energy and nutrient intakes (90 to $150 \mathrm{kcal} / \mathrm{kg} /$ day and 1.5 to $4 \mathrm{~g} / \mathrm{kg}$ /day of proteins) according to the infants' growth pattern; this approach prevented a significant fall in weight-for-ages $z$-scores at 4 months of age and improved weight-for-age and height-for-age $z$-scores at 12 months of age in the intervention group compared to controls [28].

Several concerns exist about possible complications of feeding infants with complex cardiac defects, such as hypoplastic left heart syndrome (HLHS) or single ventricle (SV) [33]. However, preoperative feeding seems to be feasible also in these situations, and some authors have developed specific feeding protocols for the preoperative phase [27]. Among these, Slicker et al. have proposed a nutritional algorithm for infants with HLHS or SV before cardiac surgery, recommending the introduction of enteral feeds in hemodynamically stable patients, even if an umbilical artery catheter (UAC) is in place and prostaglandin (PGE) infusion is ongoing [19]. Furthermore, Fullong-Dillard et al. have found that newborns undergoing biventricular cardiac surgery who received enteral nutrition preoperatively achieved the target feeding volume $(135 \mathrm{~mL} / \mathrm{kg} /$ day $)$ earlier and required postoperative parental nutrition for shorter periods [27].

Food intolerance, fluid intake restriction, and the frequent periods of feeding withholding that characterize the preoperative phase contribute to hinder the achievement of an adequate nutritional support. Disruptions of the enteral feeding plans are frequent among CHD infants: a retrospective study documented that 1 in 5 experienced feeding interruptions, which were mainly related to common procedures such as heart catheterization, brain magnetic resonance imaging, positioning of central lines, gastrostomy and chest tubes, or to the development of GI complications [36]. In a study performed at the Boston Children's Hospital, the implementation of a nutritional protocol specifically designed to guide clinicians in the feeding management of CHD infants resulted in a significant reduction of feeding interruptions ( 3 vs. 51 before the feeding protocol introduction, $p<0.0001$ ), and in a decreased time to reach the energy targets ( 1 vs. 4 days, $p<0.001)$, which were achieved by almost all (99\%) the infants managed with this new feeding protocol compared to only $31 \%$ prior to the protocol introduction [39].

The onset of food intolerance plays a key role in hindering the achievement of full enteral feeding in CHD infants. Signs and symptoms of food intolerance in neonates with heart disease are not well defined [40], and different studies provide different def- 
initions $[25,30,39,41,42]$. The most common clinical parameters used to identify feeding intolerance are abdominal pain and distension, vomiting, decreased or abolished bowel sounds or movements, and increased residual gastric volumes, which appear as a poor marker to guide the decision to continue, hold, or stop enteral nutrition [18,31,43]. Serum lactate could be used as a marker of intestinal splanchnic perfusion, with raised levels indicating an increased risk of GI complications; however, lactate's cut-off value predictive of such complications in CHD infants is unknown, limiting the application of this biomarker in routine clinical practice [31]. Near-infrared spectroscopy (NIRS) has been largely adopted in neonatal ICU settings for the continuous monitoring of oxygen delivery at multiple sites, including the splanchnic district [44]; in preterm neonates, splanchnic NIRS monitoring has yield promising results for the prediction of GI complications [45-47]. In CHD infants, NIRS-derived mesenteric oxygenation following cardiac surgery has shown a reliable correlation with serum lactate and systemic mixed venous saturation [48]. The role of NIRS for the evaluation of mesenteric oxygenation in relation to enteral feeding in CHD infants has also been investigated. In neonates undergoing biventricular repair or SV palliation, postsurgical NEC development was associated with a significantly lower mesenteric oxygenation at enteral feeding initiation [49]; of note, all the NEC cases occurred in SV infants. Similar results have been also reported by Iliopoulos et al., who monitored mesenteric oxygenation at ICU admission after cardiac surgery on $50 \mathrm{CHD}$ children $<10 \mathrm{~kg}$, observing a significant inverse correlation between mesenteric oxygenation at admission and the time needed to establish enteral feeds. Moreover, the authors suggested a cut-off value of $72 \%$ be proposed to identify with a $78 \%$ sensitivity and $68 \%$ specificity infants at risk of developing GI complications-namely, NEC and feeding intolerance [50].

Nutritional status should be assessed by performing serial anthropometric measurements and laboratory investigations aimed at optimizing the nutritional support during hospital stay. Baseline weight, length, weight/length, mid-upper arm circumference, and head circumference, preferably expressed as $z$-scores [18,31], should be recorded at the admission and weekly $[10,23]$. In CHD infants, total body weight may not reflect the real growth, as they could experience a fluid overload primarily related to the heart condition. The assessment of the body composition could better correlate with clinical outcomes. Body fat mass can be estimated by mid-upper arm circumference, lean mass by body length, and cerebral growth by head circumference [51]; a lower adiposity has been associated with a delayed recovery, a prolonged need for mechanical ventilation, and for vasoactive treatments [52].

Different biochemical parameters should be evaluated to obtain a complete overview of the nutritional status in CHD infants. Serum proteins such as albumin and prealbumin may respectively reflect a chronic or acute undernourishment, which is in turn associated to worse cardiac function [52]. Due to its long half-life (14-20 days), albumin is a marker of chronic malnutrition, although its level can be affected by dehydration, sepsis, trauma, liver disease, and albumin replacement. Prealbumin, also known as transthyretin or thyroxinebinding prealbumin, has a half-life life of $24-48 \mathrm{~h}$ and thus reflects acute protein intakes. This protein is synthetized by the liver and excreted by the kidneys, so its values may be altered in cases of renal or liver disease $[51,53]$. Blood urea nitrogen (BUN) may better correlate with protein intake during enteral feeding in clinically stable newborns; however, BUN may be influenced by renal function, hydration status, and amino acid oxidation for energy production in critically ill patients [54].

Several factors are usually considered when planning to start preoperative enteral feeding. These include, but are not limited to, the risk of NEC, ongoing PGE, and the presence of an UAC.

\subsection{Necrotizing Enterocolitis}

NEC is a rare condition in term newborns without CHD; however, the disease is at least 10-100 times more common in CHD infants [33], with an estimated incidence ranging from $1.6 \%$ to $9 \%[24,33,55-57]$ and mortality rates between $6.8 \%$ and $24 \%$ [24,55]. 
The pathophysiology of NEC in term newborns with CHD is different compared to preterm infants: the decreased cardiac output, congestive heart failure, shock, and cardiac surgery and bypass contribute to reduce intestinal perfusion and oxygen delivery, thus making NEC a distinct pathological entity in this population $[33,55,58]$. Moreover, NEC onset in CHD infants usually occurs in the first seven days of life and typically involves the colon, while in preterm infants the small intestine and ileocecal region are more frequently involved [33,59].

The high risk of NEC in infants with CHD has always represented a limitation to achieve a shared consensus on enteral feeding practice for infants undergoing CHD surgery. However, increasing evidence supports the feasibility of preoperative enteral feeding in neonates with CHD even when the risk of NEC is taken into account [19,23,24,60-62], and the use of standardized feeding protocols has proven to reduce the incidence and severity of NEC in this population [63]. Of note, a relationship between time of enteral feeding initiation, increasing feeding volume and velocity rates, the density of milk, and the development of postoperative NEC has not been yet documented [55].

A retrospective study reported a similar prevalence of NEC (approximately 9\%) in infants with CHD who received preoperative enteral feeds, either trophic or at higher intakes [24]. Natarajan et al. found only two NEC cases (equal to 3\% of the studied population) in their cohort of CHD infants who received an intake of at least $100 \mathrm{~mL} / \mathrm{kg} /$ day before surgery [61].

The risk of NEC is higher in infants with ductal-dependent anomalies, such as critical aortic stenosis, interrupted aortic arch, coarctation of the aorta, and HLHS; in particular, the latter condition has been associated with an estimated NEC incidence ranging between $7.6 \%$ and $18 \%[32,33,56,64]$. The decision about feeding these infants before surgery is usually based on the experience of the center and of clinicians, and also relies on the assessment of the characteristics of the transductal shunt and on the abovementioned biochemical parameters [65]. In a large Swedish cohort of 444 newborns with ductal-dependent systemic circulation, 46 out of 47 infants with HLHS were enterally fed prior to surgery, receiving at least $45 \mathrm{~mL} / \mathrm{kg}$ / day of milk, and no cases of preoperative NEC were observed [60].

Given the different etiology, both short-term complications, such as bowel perforation, need for surgery, and sepsis, and long-term issues (e.g., development of strictures or short bowel syndrome) are less common in CHD infants compared to those without this condition [66]. Furthermore, the occurrence of NEC in infants with CHD has not been associated with increased mortality rates, regardless of CHD type and severity [56,57]. A potential explanation for the better prognosis of NEC in this population could be related to the close clinical monitoring of these infants, which allows a prompt NEC diagnosis and intervention $[57,66]$.

\subsection{Treatment with Prostaglandin}

PGEs are a group of physiologically active lipid compounds called eicosanoids that are used to maintain the ductus arteriosus patent in neonates with ductal-dependent CHD in order to promote mixing of pulmonary and systemic blood flow or to improve pulmonary or systemic circulation [67]. Nevertheless, the resulting hemodynamic disturbances of post-ductal systemic blood flow may lead to splanchnic hypoperfusion, thus increasing the risk of NEC [68]. Hence, due to the potential risk of intestinal complications, many clinicians prefer to avoid enteral feeding during PGE infusion $[19,36,55,65]$.

Willis et al. have reported adequate feeding tolerance in term infants with ductdependent CHD during PGE treatment, except for one infant with bidirectional shunt through the ductus arteriosus [25]. As to NEC, Becker et al. found a $0.3 \%$ incidence of this condition in term infants with ductal-dependent CHD who were enterally fed while on PGE [69], and Day et al. observed an even lower incidence in their cohort, documenting no association between enteral feeding and NEC occurrence during PGE treatment [70]. 


\subsection{Presence of an Umbilical Arterial Catheter}

A UAC in place represents another postulated risk factor for the development of NEC: by reducing the aortic lumen, the UAC may decrease the superior mesenteric artery blood flow, thus increasing the risk of mesenteric arterial thrombosis [71-73]. In some ICUs, enteral feeding is avoided as long as the UAC is in place $[30,65]$, whereas in other settings, feeding in the presence of UAC is considered a safe practice. One trial [74] and a prospective observational study [75] in preterm neonates found that having a UAC in situ did not affect mesenteric blood flow or lead to greater rates of feed intolerance or NEC. In the study by Alten et al., 76 out of 99 term CHD infants with a UAC in place received enteral feeds pre- and/or postoperatively: of the 8 cases of NEC documented in the whole study cohort, consisting of 251 infants, only 2 occurred in the UAC cohort [16].

The very recent position statement by the ESPNIC strongly supports the provision of enteral nutrition in term neonates with CHD, even with a UAC in place and during PGE infusion, providing a close monitoring of the infants [31].

\section{Postoperative Feeding Management}

Due to the high incidence of growth failure and GI complications in infants requiring surgery for $\mathrm{CHD}$, there has been great interest in developing specific postoperative feeding protocols. Braudis et al. reported that the implementation of a postoperative feeding protocol in infants with HLHS decreased the incidence of late onset sepsis, the time to achieve the goal caloric intake, and the need for parental nutrition when compared to historical controls [26].

In the postoperative period, it is common for CHD infants to have an open sternotomy for several days and to experience extracardiac complications such as respiratory failure, chylothorax, renal failure, and neurologic impairment, thus raising concerns for enteral feeding. As per preoperative feeding, an early initiation of feeding after cardiac surgery and the existence of a postoperative feeding protocol have been associated with improved growth [26] and decreased length of hospital stay [30]. However, since there are few data evaluating the relation between postoperative feeding and outcomes, practices on feeding initiation and advancement after CHD surgery are often anecdotal and institution-based [10]. Consistently, Alten et al. observed a great variability in feeding practices across cohorts and centers. The timing for starting postoperative enteral feeding varied significantly, with a median time of 2 (range 1-4) postoperative days. Initiation of postoperative feeds was delayed in patients after stage I palliation for HLHS, who are often hemodynamically unstable and require vasoactive medications and mechanical ventilation for prolonged periods. Postoperative feeds were initiated in $35 \%$ of patients before extubation (range across institutions: 21-61\%). Patients who underwent aortopulmonary shunt placement received enteral feeding $19 \%$ of the time during their ICU stay, and $55 \%$ of patients with HLHS were fed while mechanically ventilated [16].

Schwalbe-Terilli et al. evaluated the caloric intake of 100 neonates receiving enteral nutrition after cardiac surgery. The patient group were separated into biventricular cardiac defects and functional single ventricle. The center practice was to avoid enteral feeds in infants on PGE or with a UAC. Their practice was to advance feeds slowly over a period of 48 to $72 \mathrm{~h}$ to a volume of $100 \mathrm{~mL} / \mathrm{kg} / \mathrm{d}$, then increasing caloric density to 24 to $27 \mathrm{kcal} / \mathrm{oz}$ with a goal of 120 to $150 \mathrm{~mL} / \mathrm{kg} / \mathrm{d}$. Feeds were initiated as boluses given through a nasogastric tube before attempting oral feeding. In this study, a caloric intake of $100 \mathrm{kcal} / \mathrm{kg}$ was achieved on $48.4 \%$ of days of enteral feeding, and $120 \mathrm{kcal} / \mathrm{kg}$ was achieved in only $19.7 \%$ of feeding days. The authors reported a median weight change during the period of enteral feeding of $-20 \mathrm{~g}$, which was likely affected by their practice of discontinuing parenteral nutrition $(\mathrm{PN})$ at $100 \mathrm{~mL} / \mathrm{kg} / \mathrm{d}$ of enteral nutrition or when the central venous line was removed [36].

The exact caloric requirements of infants with CHD in the postoperative period are difficult to establish. Commonly used predictive equations do not provide accurate estimates of energy requirement in individual patients during the highly dynamic postoperative 
phase. Although indirect calorimetry can best estimate energy requirements in children with CHD, it is available in a minority of ICUs, and its applicability during the acute postoperative phase is hindered by high $\mathrm{FiO} 2$ requirements, endotracheal tube leaks, pleural air leaks, or intracardiac shunting [31]. Measurement of nitrogen balance is the recommended method to determine minimal protein requirement. During the early postoperative period, daily measurements of resting energy expenditure using indirect calorimetry and of nitrogen balance in each individual child would be of great value to optimize energy and protein intakes in order to meet their requirements [76].

With regard to the role of type of cardiac defect on enteral feeding management, a few previous studies have examined the incidence and clinical impact of GI morbidity among neonates with HLHS following the first stage palliation [32,77]. In the study by Jeffries and colleagues, GI complications occurred in 48/117 infants and included NEC, need for home feeding tubes, and prolonged hospital stay for nutritional support [32]. In another study comparing infants with HLHS and transposition of great arteries (TGA), the time needed to achieve full caloric intakes was significantly longer in the HLHS group (24 vs. 12 days, respectively; $p<0.001$ ) [77]. In addition, infants with HLHS had a higher incidence of feeding-related complications such as reflux disease, aspiration, and poor suck/swallow compared to those with TGA ( $48 \%$ vs. $4 \%$, respectively; $p=0.001)$. A significantly higher proportion of the TGA infants ( $76.9 \%$ vs. $25.9 \%)$ were fed orally at discharge [32,77].

\section{Breastfeeding and Role of Milk Type}

The exclusive source of nourishment recommended by the World Health Organization up to 6 months of life and as a complementary food for the first two years of life is breast milk [78], thanks to its nutritional and functional benefits [79]. Despite evidence supporting the beneficial effects of HM in vulnerable high-risk population such as preterm infants, there have been few studies assessing the benefits of HM in infants with CHD. A single-center retrospective cohort study of 546 infants with complex CHD evaluated potential feed-related risk factors for NEC in the preoperative period. The authors found that an exclusive unfortified HM diet was associated with a significantly lower risk of preoperative NEC in a multivariable regression model controlling for cardiac lesion, race, feeding volume, birth weight, gestational age, presurgery, and pre-NEC inotrope use [80].

Nevertheless, the rate of direct breastfeeding in infants with CHD is low due to the risk of aspirations due to pharyngo-laryngeal incoordination and the concerns related to their hemodynamic instability [81]. Despite these concerns, a comparative study between breastfed and formula bottle-fed infants reported that not only children with CHD were able to breastfeed, but they also had a better weight gain compared to bottle-fed infants [82]. Since many of these newborns need a restriction of fluids and receive diuretic therapy, a precise monitoring of the intake volume is mandatory. The exact quantification of enteral volumes can be achieved also in breastfed infants: according to some authors, the breastfeeding weight test, consisting of the weight difference before and after feeding, could be useful in this respect and would also encourage the mother to provide her own milk [81].

Despite HM benefits, mother's own milk (MOM) provision to critical infants with CHD is hindered by several factors, such as the separation of the mother-infant dyad after delivery, the stressful postpartum environment for both the mother and the infant, and the lack of lactation support. Maternal support, prenatal breastfeeding education, mothers' access to a hospital-grade breast pump and facilities, and medical staff education have all been found to be effective in promoting HM provision to infants with CHD [83].

When MOM is not available soon after birth or is not sufficient to fulfil enteral requirements, a reasonable alternative could be donor milk (DHM). In analogy with preterm infants, for whom DHM constitutes the optimal alternative to MOM, the use of DHM should also be implemented for CHD infants in light of its role in promoting feeding tolerance and reducing the risk of NEC compared to formula $[84,85]$. In a very recent single-center, retrospective cohort study, the impact of a multi-interventional nutrition program on clinical outcomes in newborns facing surgery for $\mathrm{CHD}$ was evaluated: after the 
introduction of a DHM program, significantly more patients received DHM or expressed breast milk in both the preoperative and postoperative periods. Moreover, weight-forage $z$-score improvement from birth to hospital discharge obtained with the institution of a postoperative feeding protocol were maintained after the introduction of the DHM program [62].

Since infants with CHD have a high energy expenditure and need fluid intake restriction as part of their management to prevent adverse clinical outcomes, including NEC and mortality, several studies have evaluated the potential role of high-calorie formulas to reach the nutritional requirement needed for proper growth. The use of an energy enriched formula or a protein dense formula, compared to standard formula $(1.4 \mathrm{~g} / 100 \mathrm{~mL}$, $67 \mathrm{kcal} / 100 \mathrm{~mL}$ ), resulted in a faster achievement of the nutritional goal with a higher weight gain and increased levels of serum albumin and amino acids. The only documented side effect was an initial diarrhea, probably related to the higher osmolarity of the enriched formula $[42,86,87]$. On the contrary, an observational study including 122 infants with biventricular and univentricular cardiac defects undergoing surgery showed no difference in postoperative growth and hospitalization length between infants receiving MOM, a standard formula $(67 \mathrm{kcal} / 100 \mathrm{~mL})$, or a preterm formula $(80 \mathrm{kcal} / 100 \mathrm{~mL})$ [88].

\section{Feeding Issues}

Feeding issues and delays in achieving full oral nutrition are frequent in infants with CHD and are still observed at two years of age in $22 \%$ of infants undergoing neonatal cardiac surgery [89]. Thus, many children depend on prolonged enteral nutrition, either through the nasogastric tube or the gastrostomy, to meet their nutritional needs during hospitalization and often also after hospital discharge $[8,9,16]$.

The type and severity of heart disease affects the acquisition of feeding skills; specifically, children with cyanotic heart lesions face longer delays in taking their first oral feed and in reaching the goal intake volume compared to children with non-cyanotic heart disease [90]. Children with single ventricle physiology, especially HLHS, often need prolonged enteral feeding, either through a nasogastric tube or a gastrostomy $[7,61,77,91,92]$. A more complex surgical approach even with the use of cardiopulmonary bypass turns out to be decisive in increasing the time to achieve full oral feeds [9,90]. Comorbidities such as gastroesophageal reflux disease, postoperative vocal cords paralysis, genetic syndromes, and a longer need of interrupting enteral feeds are associated with the need for device-assisted feeding and are predictors of reduced oral feeding capacity [91,93]. Hospital-dependent factors also influence the development of oral feeding skills, including the implementation of preoperative feeding [93] and the time to initiate postoperative enteral nutrition [91,94]. Instead, there are controversies in the literature about the role of prolonged intubation duration, as most studies describe invasive respiratory support as a risk factor for developing feed difficulties $[9,90,91,94,95]$, while a study claims it has no influence on oral motor skills [96].

It is unclear whether there is an optimal route in terms of efficacy and safety for providing enteral feeding to CHD infants, and this leads to a high variability between centers in choosing a nasogastric tube or a gastrostomy [16]. In a cohort of infants with single ventricle heart defects, no significant association was found between feeding modality and change in weight-for-age $z$-score after stage 1 surgery [97]; other authors found preemptive gastrostomy placement to be associated with improved survival to stage 2 surgery operation but not with shorter hospitalization or better growth [98].

The assessment of oro-motor skills, aspiration risks and the consequent application of a specific intervention to improve oral feeding skills in newborns facing surgery for CHD has resulted in improved weight gain and fewer gastrostomy placements at discharge [62,91].

Children with CHD have an increased risk of abnormal neurological development since arterial saturation and brain oxygenation associated with neurological development can be compromised by unstable hemodynamics [99]. Growing literature has highlighted the impact of feeding mode on neurodevelopmental outcomes in children with CHD [100]. 
The inability to achieve full oral nutrition and the prolonged need for enteral feeding tubes or gastrostomy are associated with delays in cognitive, communicative, and motor domains at 6,12 , and 24 months of age [8,101-103].

Nutritional issues in infants with CHD may persist after hospital discharge. Several studies documented a high rate of failure to thrive in infants with CHD after discharge, both in severe and milder forms [8].

Hence, during hospital stay and after discharge it is necessary to perform a close monitoring of growth and nutrition of infants with CHD, especially in the first year of life, since longitudinal and head circumference growth may experience delay for one year or more [85].

\title{
7. Conclusions
}

Despite advances in neonatal and cardiac intensive care, infants with CHD have a greater risk of malnutrition and growth deficit, as well as of negative long-term neurodevelopmental outcomes. Although optimal nutrition is considered essential to improve outcomes in critically ill infants, there is lack of high-quality evidence to guide enteral nutrition in this high-risk population with increased nutritional challenge. Therefore, a wide variability in feeding management exists worldwide, across clinicians, institutions, and countries. Pathophysiology of nutritional and metabolic changes is age dependent. However, available observations and recommendations for cardiac infants partially rely on studies in preterm infants, as evidence from term infants is scarce. Acknowledging these limitations, currently available literature highlights the role of nutritional management and suggests changes in current practice that are likely to improve nutrition status and outcomes of infants with CHD (Box 1). Large, well-designed studies assessing standardized clinically relevant outcomes are needed to provide robust evidence and shared recommendations and to achieve an implementation of evidence into current practice.

Box 1. Suggested approaches emerged from current literature to improve nutritional status and out-comes in infants with congenital heart disease.

- Implementation of enteral feeding protocols, both preoperative and postoperative, with clearly stated reasons to withhold enteral feeds and definitions of feeding intol-erance.

- $\quad$ Early minimal enteral feeding within $24 \mathrm{~h}$ of admission.

- Enteral feeding should be considered in term infants with umbilical arterial catheters and during prostaglandin infusion.

- $\quad$ Enteral feeding should be considered in stable term infants on hemodynamic support.

- Frequent assessment of nutritional status and growth parameters.

- Assessment and support of oro-motor skills.

- $\quad$ Promotion and support of breastfeeding and provision of mother's own milk (MOM); if MOM is not available, consider donor milk (if available).

\begin{abstract}
Author Contributions: Conceptualization, L.C., S.M. and A.A.; methodology, A.A., S.M. and I.B.; writing—original draft preparation, S.M., I.B. and M.A.; writing—review and editing, A.A., S.G. and L.R.; supervision, A.D. and L.C. All authors have read and agreed to the published version of the manuscript.
\end{abstract}

Funding: This research received no external funding.

Conflicts of Interest: The authors declare no conflict of interest.

\section{References}

1. Ferencz, C.; Rubin, J.D.; McCarter, R.J.; Brenner, J.I.; Neill, C.A.; Perry, L.W.; Hepner, S.I.; Downing, J.W. Congenital Heart Disease: Prevalence at Livebirth. Am. J. Epidemiol. 1985, 121, 31-36. [CrossRef]

2. Hoffman, J.I.; Kaplan, S. The Incidence of Congenital Heart Disease. J. Am. Coll. Cardiol. 2002, 39, 1890-1900. [CrossRef]

3. Van Der Linde, D.; Konings, E.E.M.; Slager, M.A.; Witsenburg, M.; Helbing, W.A.; Takkenberg, J.J.M.; Roos-Hesselink, J.W. Birth Prevalence of Congenital Heart Disease Worldwide: A Systematic Review and Meta-Analysis. J. Am. Coll. Cardiol. 2011, 58, 2241-2247. [CrossRef] [PubMed] 
4. Hehir, D.A.; Rudd, N.; Slicker, J.; Mussatto, K.A.; Simpson, P.; Li, S.-H.; Frommelt, M.A.; Tweddell, J.S.; Ghanayem, N.S. Normal Interstage Growth After the Norwood Operation Associated With Interstage Home Monitoring. Pediatr. Cardiol. 2012, 33, 1315-1322. [CrossRef] [PubMed]

5. Blasquez, A.; Clouzeau, H.; Fayon, M.; Mouton, J.-B.; Thambo, J.-B.; Enaud, R.; Lamireau, T. Evaluation of Nutritional Status and Support in Children with Congenital Heart Disease. Eur. J. Clin. Nutr. 2016, 70, 528-531. [CrossRef]

6. Varan, B.; Tokel, K.; Yilmaz, G. Malnutrition and Growth Failure in Cyanotic and Acyanotic Congenital Heart Disease with and without Pulmonary Hypertension. Arch. Dis. Child. 1999, 81, 49-52. [CrossRef]

7. Nydegger, A.; Bines, J.E. Energy Metabolism in Infants with Congenital Heart Disease. Nutrients 2006, 22, 697-704. [CrossRef]

8. Medoff-Cooper, B.; Ravishankar, C. Nutrition and Growth in Congenital Heart Disease: A Challenge in Children. Curr. Opin. Cardiol. 2013, 28, 122-129. [CrossRef]

9. Kogon, B.E.; Ramaswamy, V.; Todd, K.; Plattner, C.; Kirshbom, P.M.; Kanter, K.R.; Simsic, J. Feeding Difficulty in Newborns Following Congenital Heart Surgery. Congenit. Heart Dis. 2007, 2, 332-337. [CrossRef]

10. Karpen, H.E. Nutrition in the Cardiac Newborns: Evidence-based Nutrition Guidelines for Cardiac Newborns. Clin. Perinatol. 2016, 43, 131-145. [CrossRef]

11. Irving, S.Y.; Medoff-Cooper, B.; Stouffer, N.O.; Schall, J.I.; Ravishankar, C.; Compher, C.W.; Marino, B.S.; Stallings, V.A. Resting Energy Expenditure at 3 Months of Age Following Neonatal Surgery for Congenital Heart Disease. Congenit. Heart Dis. 2013, 8, 343-351. [CrossRef]

12. Li, L.; Li, K.; An, C.; Fan, J.; Guo, C.; Liang, S.; Guo, Y.; Xia, H.; Chen, X.; Zhu, Y.; et al. Identification of Risk Factors Affecting Catch-up Growth after Infant Congenital Heart Disease Surgery: Rationale and Design of a Multicentre Prospective Cohort Study in China. BMJ Open 2019, 9, e030084. [CrossRef]

13. Davies, P.S. Energy Requirements and Energy Expenditure in Infancy. Eur. J. Clin. Nutr. 1992, 46, S29-S35. [PubMed]

14. Dykman, R.A.; Casey, P.H.; Ackerman, P.T.; McPherson, W.B. Behavioral and Cognitive Status in School-Aged Children with a History of Failure to Thrive during Early Childhood. Clin. Pediatr. 2001, 40, 63-70. [CrossRef]

15. Black, M.M.; Dubowitz, H.; Krishnakumar, A.; Jr, R.H.S. Early Intervention and Recovery Among Children With Failure to Thrive: Follow-up at Age 8. Pediatrics 2007, 120, 59-69. [CrossRef]

16. Alten, J.A.; Rhodes, L.A.; Tabbutt, S.; Cooper, D.S.; Graham, E.M.; Ghanayem, N.; Marino, B.S.; Figueroa, M.I.; Chanani, N.K.; Jacobs, J.P.; et al. Perioperative Feeding Management of Neonates with CHD: Analysis of the Pediatric Cardiac Critical Care Consortium (PC4) registry. Cardiol. Young 2015, 25, 1593-1601. [CrossRef] [PubMed]

17. Lambert, L.M.; Pike, N.A.; Medoff-Cooper, B.; Zak, V.; Pemberton, V.L.; Young-Borkowski, L.; Clabby, M.L.; Nelson, K.N.; Ohye, R.G.; Trainor, B.; et al. Variation in Feeding Practices following the Norwood Procedure. J. Pediatr. 2014, 164, 237-242.e1. [CrossRef]

18. Tume, L.N.; Balmaks, R.; da Cruz, E.; Latten, L.; Verbruggen, S.; Valla, F. V Enteral Feeding Practices in Infants With Congenital Heart Disease Across European PICUs: A European Society of Pediatric and Neonatal Intensive Care Survey. Pediatr. Crit. Care Med. 2018, 19, 137-144. [CrossRef] [PubMed]

19. Slicker, J.; Sables-Baus, S.; Lambert, L.M.; Peterson, L.E.; Woodard, F.K.; Ocampo, E.C. For the National Pediatric CardiologyQuality Improvement Collaborative Feeding Work Group Perioperative Feeding Approaches in Single Ventricle Infants: A Survey of 46 Centers. Congenit. Heart Dis. 2016, 11, 707-715. [CrossRef]

20. Toole, B.J.; Toole, L.E.; Kyle, U.G.; Cabrera, A.G.; Orellana, R.A.; Coss-Bu, J.A. Perioperative Nutritional Support and MalNutrition in Infants and Children with Congenital Heart Disease. Congenit. Heart Dis. 2014, 9, 15-25. [CrossRef]

21. Larsen, B.M.K.; Goonewardene, L.A.; Field, C.J.; Joffe, A.R.; Van Aerde, J.E.; Olstad, D.L.; Clandinin, M.T. Low Energy Intakes Are Associated With Adverse Outcomes in Infants After Open Heart Surgery. J. Parenter. Enter. Nutr. 2012, 37, 254-260. [CrossRef]

22. Eskedal, L.T.; Hagemo, P.S.; Seem, E.; Eskild, A.; Cvancarova, M.; Seiler, S.; Thaulow, E. Impaired Weight Gain Predicts Risk of Late Death after Surgery for Congenital Heart Defects. Arch. Dis. Child. 2008, 93, 495-501. [CrossRef]

23. Toms, R.; Jackson, K.W.; Dabal, R.J.; Reebals, C.H.; Alten, J.A. Preoperative Trophic Feeds in Neonates with Hypoplastic Left Heart Syndrome. Congenit. Heart Dis. 2014, 10, 36-42. [CrossRef] [PubMed]

24. Scahill, C.J.; Graham, E.M.; Atz, A.M.; Bradley, S.M.; Kavarana, M.N.; Zyblewski, S.C. Preoperative Feeding and Necrotizing Enterocolitis: Is the Fear Justified? World J. Pediatr. Congenit. Heart Surg. 2017, 8, 62-68. [CrossRef]

25. Willis, L.; Thureen, P.; Kaufman, J.; Wymore, E.; Skillman, H.; da Cruz, E. Enteral Feeding in Prostaglandin-Dependent Neonates: Is It a Safe Practice? J. Pediatr. 2008, 153, 867-869. [CrossRef]

26. Braudis, N.J.; Curley, M.A.Q.; Beaupre, K.; Thomas, K.C.; Hardiman, G.; Laussen, P.; Gauvreau, K.; Thiagarajan, R.R. Enteral Feeding Algorithm for Infants with Hypoplastic Left Heart Syndrome Poststage I Palliation. Pediatr. Crit. Care Med. 2009, 10, 460-466. [CrossRef]

27. Furlong-Dillard, J.; Neary, A.; Marietta, J.; Jones, C.; Jeffers, G.; Gakenheimer, L.; Puchalski, M.; Eckauser, A.; Delgado-Corcoran, C. Evaluating the Impact of a Feeding Protocol in Neonates before and after Biventricular Cardiac Surgery. Pediatr. Qual. Saf. 2018, 3, e080. [CrossRef] [PubMed]

28. Marino, L.V.; Johnson, M.J.; Davies, N.J.; Kidd, C.S.; Fienberg, J.; Richens, T.; Bharucha, T.; Beattie, R.M.; Darlington, A.-S.E. Improving Growth of Infants with Congenital Heart Disease Using a Consensus-Based Nutritional Pathway. Clin. Nutr. 2020, 39 , 2455-2462. [CrossRef] [PubMed] 
29. Marino, L.V.; Johnson, M.J.; Hall, N.J.; Davies, N.J.; Kidd, C.S.; Daniels, M.L.; Robinson, J.E.; Richens, T.; Bharucha, T.; Darlington, A.-S.E. The Development of a Consensus-Based Nutritional Pathway for Infants with CHD before Surgery Using a Modified Delphi Process. Cardiol. Young 2018, 28, 938-948. [CrossRef] [PubMed]

30. Del Castillo, S.L.; McCulley, M.E.; Khemani, R.G.; Jeffries, H.E.; Thomas, D.W.; Peregrine, J.; Wells, W.J.; Starnes, V.A.; Moromisato, D.Y. Reducing the Incidence of Necrotizing Enterocolitis in Neonates with Hypoplastic Left Heart Syndrome with the Introduction of an Enteral Feed Protocol. Pediatr. Crit. Care Med. 2009, 11, 373-377. [CrossRef] [PubMed]

31. Tume, L.N.; Valla, F.V.; Joosten, K.; Chaparro, C.J.; Latten, L.; Marino, L.V.; MacLeod, I.; Moullet, C.; Pathan, N.; Rooze, S.; et al. Nutritional Support for Children during Critical Illness: European Society of Pediatric and Neonatal Intensive Care (ESPNIC) Metabolism, Endocrine and Nutrition Section Position Statement and Clinical Recommendations. Intensiv. Care Med. 2020, 46, 411-425. [CrossRef] [PubMed]

32. Jeffries, H.E.; Wells, W.J.; Starnes, V.A.; Wetzel, R.C.; Moromisato, D.Y. Gastrointestinal Morbidity After Norwood Palliation for Hypoplastic Left Heart Syndrome. Ann. Thorac. Surg. 2006, 81, 982-987. [CrossRef]

33. Mcelhinney, D.B.; Hedrick, H.L.; Bush, D.M.; Pereira, G.R.; Stafford, P.W.; Gaynor, J.W.; Spray, T.L.; Wernovsky, G. Necrotizing Enterocolitis in Neonates With Congenital Heart Disease: Risk Factors and Outcomes. Pediatrics 2000, 106, 1080-1087. [CrossRef]

34. Floh, A.A.; Slicker, J.; Schwartz, S.M. Nutrition and Mesenteric Issues in Pediatric Cardiac Critical Care. Pediatr. Crit. Care Med. 2016, 17, S243-S249. [CrossRef] [PubMed]

35. Berseth, C.L.; Bisquera, J.A.; Paje, V.U. Prolonging Small Feeding Volumes Early in Life Decreases the Incidence of Necrotizing Enterocolitis in Very Low Birth Weight Infants. Pediatrics 2003, 111, 529-534. [CrossRef]

36. Schwalbe-Terilli, C.R.; Hartman, D.H.; Nagle, M.L.; Gallagher, P.R.; Ittenbach, R.F.; Burnham, N.B.; Gaynor, J.W.; Ravishankar, C. Enteral Feeding and Caloric Intake in Neonates After Cardiac Surgery. Am. J. Crit. Care 2009, 18, 52-57. [CrossRef] [PubMed]

37. Schwarz, S.M.; Gewitz, M.H.; See, C.C.; Berezin, S.; Glassman, M.S.; Medow, C.M.; Fish, B.C.; Newman, L.J. Enteral Nu-Trition in Infants with Congenital Heart Disease and Growth Failure. Pediatrics 1990, 86, 368-373.

38. Golden, M.H. Proposed Recommended Nutrient Densities for Moderately Malnourished Children. Food Nutr. Bull. 2009, 30, S267-S342. [CrossRef] [PubMed]

39. Hamilton, S.; McAleer, D.M.; Ariagno, K.; Barrett, M.; Stenquist, N.; Duggan, C.P.; Mehta, N.M. A Stepwise Enteral Nutrition Algorithm for Critically III Children Helps Achieve Nutrient Delivery Goals. Pediatr. Crit. Care Med. 2014, 15, 583-589. [CrossRef] [PubMed]

40. Tume, L.N.; Valla, F.V. A Review of Feeding Intolerance in Critically Ill Children. Eur. J. Nucl. Med. Mol. Imaging 2018, 177, 1675-1683. [CrossRef]

41. Panchal, A.K.; Manzi, J.; Connolly, S.; Christensen, M.; Wakeham, M.; Goday, P.S.; Mikhailov, T.A. Safety of Enteral Feedings in Critically Ill Children Receiving Vasoactive Agents. J. Parenter. Enter. Nutr. 2014, 40, 236-241. [CrossRef] [PubMed]

42. Cui, Y.; Li, L.; Hu, C.; Shi, H.; Li, J.; Gupta, R.K.; Liang, H.; Chen, X.; Gong, S. Effects and Tolerance of Protein and Ener-gyEnriched Formula in Infants Following Congenital Heart Surgery: A Randomized Controlled Trial. J. Parenter. Enter. Nutr. 2018, 42, 196-204.

43. Kuppinger, D.D.; Rittler, P.; Hartl, W.H.; Rüttinger, D. Use of Gastric Residual Volume to Guide Enteral Nutrition in Critically Ill Patients: A Brief Systematic Review of Clinical Studies. Nutrients 2013, 29, 1075-1079. [CrossRef] [PubMed]

44. Martini, S.; Corvaglia, L. Splanchnic NIRS Monitoring in Neonatal Care: Rationale, Current Applications and Future Perspectives. J. Perinatol. 2018, 38, 431-443. [CrossRef] [PubMed]

45. Fortune, P.-M.; Wagstaff, M.; Petros, A.J. Cerebro-Splanchnic Oxygenation Ratio (CSOR) Using near Infrared Spectroscopy May Be Able to Predict Splanchnic Ischaemia in Neonates. Intensiv. Care Med. 2001, 27, 1401-1407. [CrossRef]

46. Schat, T.E.; Schurink, M.; Van Der Laan, M.E.; Hulscher, J.B.F.; Hulzebos, C.V.; Bos, A.F.; Kooi, E.M.W. Near-Infrared Spectroscopy to Predict the Course of Necrotizing Enterocolitis. PLoS ONE 2016, 11, e0154710. [CrossRef]

47. Martini, S.; Aceti, A.; Beghetti, I.; Faldella, G.; Corvaglia, L. Feed-related Splanchnic Oxygenation in Preterm Infants With Abnormal Antenatal Doppler Developing Gut Complications. J. Pediatr. Gastroenterol. Nutr. 2018, 66, 755-759. [CrossRef]

48. Kaufman, J.; Almodovar, M.C.; Zuk, J.; Friesen, R.H. Correlation of Abdominal Site near-Infrared Spectroscopy with Gastric Tonometry in Infants Following Surgery for Congenital Heart Disease. Pediatr. Crit. Care Med. 2008, 9, 62-68. [CrossRef]

49. DeWitt, A.G.; Charpie, J.R.; Donohue, J.E.; Yu, S.; Owens, G.E. Splanchnic Near-Infrared Spectroscopy and Risk of Necrotizing Enterocolitis After Neonatal Heart Surgery. Pediatr. Cardiol. 2014, 35, 1286-1294. [CrossRef]

50. Iliopoulos, I.; Branco, R.G.; Brinkhuis, N.; Furck, A.; Larovere, J.; Cooper, D.S.; Pathan, N. Mesenteric near-Infrared Spec-Troscopy and Risk of Gastrointestinal Complications in Infants Undergoing Surgery for Congenital Heart Disease. Cardiol. Young 2016, 26, 772-780. [CrossRef] [PubMed]

51. Pereira-Da-Silva, L.; Virella, D.; Fusch, C. Nutritional Assessment in Preterm Infants: A Practical Approach in the NICU. Nutrients 2019, 11, 1999. [CrossRef]

52. Radman, M.; Mack, R.; Barnoya, J.; Castañeda, A.; Rosales, M.; Azakie, A.; Mehta, N.; Keller, R.; Datar, S.; Oishi, P.; et al. The Effect of Preoperative Nutritional Status on Postoperative Outcomes in Children Undergoing Surgery for Congenital Heart Defects in San Francisco (UCSF) and Guatemala City (UNICAR). J. Thorac. Cardiovasc. Surg. 2014, 147, 442-450. [CrossRef] [PubMed]

53. Mehta, N.M.; Compher, C.; Directors, A.B.O.A.S.P.E.N. Clinical Guidelines: Nutrition Support of the Critically Ill Child. J. Parenter. Enter. Nutr. 2009, 33, 260-276. [CrossRef] [PubMed] 
54. Roggero, P.; Giannì, M.L.; Morlacchi, L.; Piemontese, P.; Liotto, N.; Taroni, F.; Mosca, F. Blood Urea Nitrogen Concentrations in Low-birth-weight Preterm Infants During Parenteral and Enteral Nutrition. J. Pediatr. Gastroenterol. Nutr. 2010, $51,213-215$. [CrossRef]

55. Iannucci, G.J.; Oster, M.E.; Mahle, W.T. Necrotising Enterocolitis in Infants with Congenital Heart Disease: The Role of Enteral Feeds. Cardiol. Young 2012, 23, 553-559. [CrossRef] [PubMed]

56. Lau, P.E.; Cruz, S.M.; Ocampo, E.C.; Nuthakki, S.; Style, C.C.; Lee, T.C.; Wesson, D.E.; Olutoye, O.O. Necrotizing Entero-Colitis in Patients with Congenital Heart Disease: A Single Center Experience. J. Pediatr. Surg. 2018, 53, 914-917. [CrossRef]

57. Mukherjee, D.; Zhang, Y.; Chang, D.C.; Vricella, L.A.; Brenner, J.I.; Abdullah, F. Outcomes Analysis of Necrotizing Entero-Colitis within 11958 Neonates Undergoing Cardiac Surgical Procedures. Arch. Surg. 2010, 145, 389-392. [CrossRef]

58. Giannone, P.J.; Luce, W.A.; Nankervis, C.A.; Hoffman, T.M.; Wold, L.E. Necrotizing Enterocolitis in Neonates with Con-Genital Heart Disease. Life Sci. 2008, 82, 341-347. [CrossRef]

59. Bubberman, J.; Van Zoonen, A.; Bruggink, J.; Van Der Heide, M.; Berger, R.; Bos, A.; Kooi, E.; Hulscher, J. Necrotizing Enterocolitis Associated with Congenital Heart Disease: A Different Entity? J. Pediatr. Surg. 2019, 54, 1755-1760. [CrossRef] [PubMed]

60. Nordenström, K.; Lannering, K.; Mellander, M.; Elfvin, A. Low Risk of Necrotising Enterocolitis in Enterally Fed Neonates with Critical Heart Disease: An Observational Study. Arch. Dis. Child. Fetal Neonatal Ed. 2020, 105, 609-614. [CrossRef] [PubMed]

61. Natarajan, G.; Anne, S.R.; Aggarwal, S. Enteral Feeding of Neonates with Congenital Heart Disease. Neonatology 2010, 98, 330-336. [CrossRef]

62. O’Neal Maynord, P.; Johnson, M.; Xu, M.; Slaughter, J.C.; Killen, S.A.S. A Multi-Interventional Nutrition Program for Newborns with Congenital Heart Disease. J. Pediatr. 2021, 228, 66-73.e2. [CrossRef]

63. Gephart, S.M.; Moore, E.F.; Fry, E. Standardized Feeding Protocols to Reduce Risk of Necrotizing Enterocolitis in Fragile Infants Born Premature or with Congenital Heart Disease: Implementation Science Needed. Crit. Care Nurs. Clin. N. Am. 2018, 30, 457-466. [CrossRef] [PubMed]

64. Fisher, J.G.; Bairdain, S.; Sparks, E.A.; Khan, F.A.; Archer, J.M.; Kenny, M.; Edwards, E.M.; Soll, R.F.; Modi, B.P.; Yeager, S.; et al. Serious Congenital Heart Disease and Necrotizing Enterocolitis in Very Low Birth Weight Neonates. J. Am. Coll. Surg. 2015, 220, 1018-1026.e14. [CrossRef] [PubMed]

65. Howley, L.W.; Kaufman, J.; Wymore, E.; Thureen, P.; Magouirk, J.K.; McNair, B.; Da Cruz, E.M. Enteral Feeding in Neonates with Prostaglandin-Dependent Congenital Cardiac Disease: International Survey on Current Trends and Variations in Practice. Cardiol. Young 2011, 22, 121-127. [CrossRef] [PubMed]

66. Pickard, S.S.; Feinstein, J.A.; Popat, R.A.; Huang, L.; Dutta, S. Short- and Long-Term Outcomes of Necrotizing Enterocolitis in Infants With Congenital Heart Disease. Pediatrics 2009, 123, e901-e906. [CrossRef]

67. Rudolph, A.M.; Heymann, M.A. Medical Treatment of the Ductus Arteriosus. Hosp. Pract. 1977, 12, 57-65. [CrossRef]

68. Kort, E.J. Patent Ductus Arteriosus in the Preterm Infant: An Update on Morbidity and Mortality. Curr. Pediatr. Rev. 2016, 12, 98-105. [CrossRef]

69. Becker, K.C.; Hornik, C.P.; Cotten, C.M.; Clark, R.H.; Hill, K.D.; Lenfestey, R.W.; Smith, P.B. Necrotizing Enterocolitis in Infants with Ductal-Dependent Congenital Heart Disease. Am. J. Perinatol. 2014, 32, 633-638. [CrossRef] [PubMed]

70. Day, T.; Dionisio, D.; Zannino, D.; Brizard, C.; Cheung, M. Enteral Feeding in Duct-Dependent Congenital Heart Disease. J. Neonatal Perinatal Med. 2019, 12, 9-12. [CrossRef]

71. Lehmiller, J.D.; Kanto, P.W.J. Relationships of Mesenteric Thromboembolism, Oral Feeding, and Necrotizing Enterocolitis. J. Pediatr. 1978, 92, 96-100. [CrossRef]

72. Mokrohisky, S.T.; Blumhagen, J.D.; Wesenberg, R.L.; Levine, R.L.; Simmons, M.A. Low Positioning of Umbilical-Artery Catheters Increases Associated Complications in Newborn Infants. N. Engl. J. Med. 1978, 299, 561-564. [CrossRef] [PubMed]

73. Rizzi, M.; Goldenberg, N.; Bonduel, M.; Revel-Vilk, S.; Amankwah, E.; Albisetti, M. Catheter-Related Arterial Thrombosis in Neonates and Children: A Systematic Review. Thromb. Haemost. 2018, 118, 1058-1066. [CrossRef]

74. Davey, A.M.; Wagner, C.L.; Cox, C.; Kendig, J.W. Feeding Premature Infants While Low Umbilical Artery Catheters Are in Place: A Prospective, Randomized Trial. J. Pediatr. 1994, 124, 795-799. [CrossRef]

75. Havranek, T.; Johanboeke, P.; Madramootoo, C.; Carver, J.D. Umbilical Artery Catheters Do Not Affect Intestinal Blood Flow Responses to Minimal Enteral Feedings. J. Perinatol. 2007, 27, 375-379. [CrossRef] [PubMed]

76. Zhang, J.; Cui, Y.; Ma, M.Z.; Luo, Y.; Chen, X.; Li, J. Energy and Protein Requirements in Children Undergoing Cardiopulmonary Bypass Surgery: Current Problems and Future Direction. J. Parenter. Enter. Nutr. 2019, 43, 54-62. [CrossRef] [PubMed]

77. Davis, D.; Davis, S.; Cotman, K.; Worley, S.; Londrico, D.; Kenny, D.; Harrison, A.M. Feeding Difficulties and Growth Delay in Children with Hypoplastic Left Heart Syndrome versus d-Transposition of the Great Arteries. Pediatr. Cardiol. 2007, 29, 328-333. [CrossRef]

78. World Health Organization. Infant and Young Child Feeding Fact Sheet 2017. Available online: http://www.who.int/ mediacentre/factsheets / fs342/en/ (accessed on 11 November 2017).

79. Kim, J.H.; Froh, E.B. What Nurses Need To Know Regarding Nutritional and Immunobiological Properties of Human Milk. J. Obstet. Gynecol. Neonatal Nurs. 2012, 41, 122-137. [CrossRef]

80. Cognata, A.; Kataria-Hale, J.; Griffiths, P.; Maskatia, S.; Rios, D.; O’Donnell, A.; Roddy, D.J.; Mehollin-Ray, A.; Hagan, J.; Placencia, J.; et al. Human Milk Use in the Preoperative Period Is Associated with a Lower Risk for Necrotizing Enterocolitis in Neonates with Complex Congenital Heart Disease. J. Pediatr. 2019, 215, 11-16.e2. [CrossRef] 
81. Gregory, C. Use of Test Weights for Breastfeeding Infants with Congenital Heart Disease in a Cardiac Transitional Care Unit: A Best Practice Implementation Project. JBI Database Syst. Rev. Implement. Rep. 2018, 16, 2224-2245. [CrossRef] [PubMed]

82. Combs, V.L.; Marino, B.L. A Comparison of Growth Patterns in Breast and Bottle-Fed Infants with Congenital Heart Disease. Pediatr. Nurs. 1993, 19, 175-179.

83. Torowicz, D.L.; Seelhorst, A.; Froh, E.B.; Spatz, D.L. Human Milk and Breastfeeding Outcomes in Infants with Congenital Heart Disease. Breastfeed. Med. 2015, 10, 31-37. [CrossRef]

84. Davis, J.A.; Spatz, D.L. Human Milk and Infants With Congenital Heart Disease: A Summary of Current Literature Supporting the Provision of Human Milk and Breastfeeding. Adv. Neonatal Care Off. J. Natl. Assoc. Neonatal Nurses 2019, 19, 212-218. [CrossRef] [PubMed]

85. Mangili, G.; Garzoli, E.; Sadou, Y. Feeding Dysfunctions and Failure to Thrive in Neonates with Congenital Heart Diseases. La Pediatr. Medica Chir. 2018, 40, 40. [CrossRef] [PubMed]

86. Taniguchi-Fukatsu, A.; Matsuoka, M.; Amagai, T. Effect of a High Density Formula on Growth and Safety in Congenital Heart Disease Infants. e-SPEN Eur. J. Clin. Nutr. Metab. 2010, 5, e281-e283. [CrossRef]

87. Scheeffer, V.A.; Ricachinevsky, C.P.; Rodrigues, N.; Tha, A.; Salamon, F.; Feij, F.; Brondani, T.G.; Sutil, A.T.; Helena, C.; Ferreira, T.; et al. Tolerability and Effects of the Use of Energy-Enriched Infant Formula After Congenital Heart Surgery: A Randomized Controlled Trial. JPEN J. Parenter Enter. Nutr. 2020, 44, 348-354. [CrossRef] [PubMed]

88. Rosti, L.; Vivaldo, T.; Butera, G.; Chessa, M.; Carlucci, C.; Giamberti, A. Postoperative Nutrition of Neonates Undergoing Heart Surgery. La Pediatr. Medica Chir. 2012, 33, 236-240.

89. Maurer, I.; Latal, B.; Geissmann, H.; Knirsch, W.; Bauersfeld, U.; Balmer, C. Prevalence and Predictors of Later Feeding Disorders in Children Who Underwent Neonatal Cardiac Surgery for Congenital Heart Disease. Cardiol. Young 2011, 21, 303-309. [CrossRef]

90. Jadcherla, S.R.; Vijayapal, A.S.; Leuthner, S. Feeding Abilities in Neonates with Congenital Heart Disease: A Retrospective Study. J. Perinatol. 2009, 29, 112-118. [CrossRef] [PubMed]

91. Indramohan, G.; Pedigo, T.P.; Rostoker, N.; Cambare, M.; Grogan, T.; Federman, M.D. Identification of Risk Factors for Poor Feeding in Infants with Congenital Heart Disease and a Novel Approach to Improve Oral Feeding. J. Pediatr. Nurs. 2017, 35, 149-154. [CrossRef]

92. Hill, G.; Silverman, A.; Noel, R.; Bartz, P.J. Feeding Dysfunction in Single Ventricle Patients with Feeding Disorder. Congenit. Heart Dis. 2013, 9, 26-29. [CrossRef]

93. Mckean, E.B.; Kasparian, N.A.; Batra, S.; Sholler, G.F.; Winlaw, D.S.; Dalby-Payne, J. Feeding Difficulties in Neonates Following Cardiac Surgery: Determinants of Prolonged Feeding-Tube Use. Cardiol. Young 2017, 27, 1203-1211. [CrossRef] [PubMed]

94. Sables-Baus, S.; Kaufman, J.; Cook, P.; Da Cruz, E.M. Oral Feeding Outcomes in Neonates with Congenital Cardiac Disease Undergoing Cardiac Surgery. Cardiol. Young 2011, 22, 42-48. [CrossRef]

95. De Souza, P.C.; Gigoski, V.S.; Etges, C.L. Findings of Postoperative Clinical Assessment of Swallowing in Infants with Congenital Heart Defect. CoDAS 2018, 30, e20170024.

96. Firpo, C.; Gasparin, M.; Teixeira, A.R.; Dornelles, S.; Bacaltchuk, T.; Levy, D.S.; Pereira, K.D.R. Evaluation of Swallowing in Infants with Congenital Heart Defect. Int. Arch. Otorhinolaryngol. 2014, 19, 055-060. [CrossRef]

97. Hill, G.D.; Hehir, D.A.; Bartz, P.J.; Rudd, N.A.; Frommelt, M.A.; Slicker, J.; Tanem, J.; Frontier, K.; Xiang, Q.; Wang, T.; et al. Effect of Feeding Modality on Interstage Growth after Stage I Palliation: A Report from the National Pediatric Cardiology Quality Improvement Collaborative. J. Thorac. Cardiovasc. Surg. 2014, 148, 1534-1539. [CrossRef] [PubMed]

98. Garcia, X.; Jaquiss, R.D.; Imamura, M.; Swearingen, C.J.; Dassinger, M.S.; Sachdeva, R. Preemptive Gastrostomy Tube Placement after Norwood Operation. J. Pediatr. 2011, 159, 602-607.e1. [CrossRef] [PubMed]

99. Hoffman, G.M.; Brosig, C.L.; Bear, L.M.; Tweddell, J.S.; Mussatto, K.A.; Information, P.E.K.F.C. Effect of Intercurrent Operation and Cerebral Oxygenation on Developmental Trajectory in Congenital Heart Disease. Ann. Thorac. Surg. 2016, 101, 708-716. [CrossRef] [PubMed]

100. Hehir, D.A.; Easley, R.B.; Byrnes, J. Noncardiac Challenges in the Cardiac ICU: Feeding, Growth and Gastrointestinal Complications, Anticoagulation, and Analgesia. World J. Pediatr. Congenit. Heart Surg. 2016, 7, 199-209. [CrossRef] [PubMed]

101. Holst, L.M.; Serrano, F.; Shekerdemian, L.; Ravn, H.B.; Guffey, D.; Ghanayem, N.S.; Monteiro, S. Impact of Feeding Mode on Neurodevelopmental Outcome in Infants and Children with Congenital Heart Disease. Congenit. Heart Dis. 2019, 14, 1207-1213. [CrossRef] [PubMed]

102. Ricci, M.F.; Alton, G.Y.; Ross, D.B.; Dicken, B.J.; Moddemann, D.M.; Robertson, C.M.; Rebeyka, I.M.; Guerra, G.G.; Atallah, J.; Dinu, I.A.; et al. Gastrostomy Tube Feeding after Neonatal Complex Cardiac Surgery Identifies the Need for Early Developmental Intervention. J. Pediatr. 2016, 169, 160-165.e1. [CrossRef] [PubMed]

103. Mussatto, K.A.; Hoffmann, R.G.; Hoffman, G.M.; Tweddell, J.S.; Bear, L.; Cao, Y.; Tanem, J.; Brosig, C.L. Risk Factors for Abnormal Developmental Trajectories in Young Children With Congenital Heart Disease. Circulation 2015, 132, 755-761. [CrossRef] [PubMed] 